\title{
The PHA Depolymerase Engineering Database: A systematic analysis tool for the diverse family of polyhydroxyalkanoate (PHA) depolymerases

\author{
Michael Knoll ${ }^{1}$, Thomas M Hamm ${ }^{1}$, Florian Wagner ${ }^{1}$, Virginia Martinez ${ }^{2}$ and \\ Jürgen Pleiss*1
}

Address: ${ }^{1}$ Institute of Technical Biochemistry, University of Stuttgart, Allmandring 31, 70569 Stuttgart, Germany and ${ }^{2}$ Department of Molecular Microbiology, Centro de Investigaciones Biologicas Ramiro de Maeztu, 9, 28040 Madrid, Spain

Email: Michael Knoll - michael.knoll@itb.uni-stuttgart.de; Thomas M Hamm - thomasmhamm@yahoo.de; Florian Wagner - florian.wagner@itb.uni-stuttgart.de; Virginia Martinez - virginiaml@cib.csic.es; Jürgen Pleiss* - juergen.pleiss@itb.unistuttgart.de

* Corresponding author

Published: 18 March 2009

BMC Bioinformatics 2009, 10:89 doi:10.1 186/147/-2105-10-89
Received: 28 November 2008

Accepted: 18 March 2009

This article is available from: http://www.biomedcentral.com/147I-2105/10/89

(C) 2009 Knoll et al; licensee BioMed Central Ltd.

This is an Open Access article distributed under the terms of the Creative Commons Attribution License (http://creativecommons.org/licenses/by/2.0), which permits unrestricted use, distribution, and reproduction in any medium, provided the original work is properly cited.

\begin{abstract}
Background: Polyhydroxyalkanoates (PHAs) can be degraded by many microorganisms using intra- or extracellular PHA depolymerases. PHA depolymerases are very diverse in sequence and substrate specificity, but share a common $\alpha / \beta$-hydrolase fold and a catalytic triad, which is also found in other $\alpha / \beta$-hydrolases.

Results: The PHA Depolymerase Engineering Database (DED, http://www.ded.uni-stuttgart.de) has been established as a tool for systematic analysis of this enzyme family. The DED contains sequence entries of 587 PHA depolymerases, which were assigned to 8 superfamilies and 38 homologous families based on their sequence similarity. For each family, multiple sequence alignments and profile hidden Markov models are provided, and functionally relevant residues are annotated.

Conclusion: The DED is a valuable tool which can be applied to identify new PHA depolymerase sequences from complete genomes in silico, to classify PHA depolymerases, to predict their biochemical properties, and to design enzyme variants with improved properties.
\end{abstract}

\section{Background}

In the past decade, polyhydroxyalkanoates (PHAs) gained industrial interest as biodegradable substitutes for nondegradable plastics. While poly $(R)$-3-hydroxybutyric acid (PHB) is the most widely studied and the best characterized PHA, a wide variety of PHAs with differences in flexibility and thermostability have been described. Many bacteria accumulate PHAs as storage compounds of carbon and energy [1-3]. PHAs have been assigned to two classes, depending on the number of carbon atoms of the monomers: short chain length PHAs $\left(\mathrm{PHA}_{\mathrm{SCL}}\right)$ with 3 to 5 carbon atoms per monomer and medium chain length PHAs $\left(\mathrm{PHA}_{\mathrm{MCL}}\right.$ ) with 6 to 15 carbon atoms per monomer. PHAs are degraded by intracellular and extracellular PHA depolymerases. Intracellular PHA depolymerases hydrolyze an endogenous carbon reservoir, the native PHA granules, consisting of the polymer with a surface layer of proteins and phospholipids. Extracellular PHA 
depolymerases degrade denatured extracellular granules which are partially crystalline and are lacking a surface layer $[4,5]$. Thus, depending on their substrate and its physical state, PHA depolymerases are grouped generally into four families: PHA depolymerases degrading the native intracellular granules $\left(\mathrm{nPHA}_{\mathrm{MCL}}\right.$ depolymerases and $\mathrm{nPHA}_{\mathrm{SCL}}$ depolymerases) and PHA depolymerases degrading the denatured extracellular PHA granules (dPHA $_{\mathrm{MCL}}$ depolymerases and $\mathrm{dPHA}_{\mathrm{SCL}}$ depolymerases). One exception of this classification is an extracellular $\mathrm{nPHA}_{\mathrm{SCL}}$ depolymerase from Paucimonas lemoignei which is active only against native PHA granules [6]. Additionally periplasmatic PHA depolymerases exist, as a PHA depolymerase from Rhodospirillum rubrum has been described recently to be located in the periplasm [7].

PHA depolymerases are carboxylesterases and belong to the $\alpha / \beta$-hydrolase fold family [5].

As member of the $\alpha / \beta$-hydrolase fold, two families including PHA depolymerases have also been described in the Pfam proteins families database [8]: the family of Esterase PHB depolymerases (Pfam accession code: PF10503) and the family describing the C-terminus of bacterial PHB depolymerases (Pfam accession code: PF06850).

With exception of a few intracellular nPHA $\mathrm{SCL}_{\mathrm{S}}$ depolymerases, all PHA depolymerases have a catalytic triad (serine histidine - aspartic acid) as active site. The catalytic serine is embedded in a GxSxG sequence motif (known as 'lipase box') as found in other $\alpha / \beta$-hydrolases. Additionally, a conserved non-catalytic histidine near the oxyanion hole is found analogous to lipases $[5,9]$. The best studied PHA depolymerases are $\mathrm{dPHA}_{\mathrm{SCL}}$ depolymerases. They share a common domain architecture consisting of a short signal peptide, a catalytic domain (including the lipase box and the oxyanion hole), a short linker domain, and a substrate binding domain [10]. Depending on the location of the lipase box on sequence level relative to the oxyanion hole, two types of catalytic domains are known. Within the sequences of type 1 catalytic domains, the oxyanion hole can be found N-terminal to the lipase box, similar to lipases. Within the sequences of type 2 catalytic domains, the oxyanion hole is found C-terminal to the catalytic triad. In contrast to $\mathrm{dPHA}_{\mathrm{SCL}}$ depolymerases, $\mathrm{dPHA}_{\mathrm{MCL}}$ depolymerases possess no substrate binding domain. In these enzymes, the $\mathrm{N}$-terminal region of the catalytic domain is assumed to function as substrate binding site [5].

The PHA depolymerase from Rhodospirillum rubrum which is described to be located in the periplasm [7] is a special case, as it has a catalytic domain similar to extracellular PHA depolymerases with a catalytic domain type 2 .

For intracellular nPHA depolymerases no particular substrate binding domain has been described so far. A few intracellular $\mathrm{nPHA}_{\mathrm{SCL}}$ depolymerases have no lipase box, but have a catalytic triad consisting of cysteine, histidine, and aspartic acid. One member of this family is the $\mathrm{nPHA}_{\mathrm{SCL}}$ depolymerase of Ralstonia eutropha [11].

Only about 30 PHA depolymerases with experimentally validated PHA depolymerase activity have been described so far. The factors which mediate the capability of depolymerases to degrade PHAs with high specificity are not yet understood. Although the sequence similarity of PHA depolymerases to other known $\alpha / \beta$-hydrolases like lipases and esterases is low and substrate specificity differs considerably, they belong to the same fold family and possess a highly conserved active site. From a systematic comparison of the PHA depolymerase family to other $\alpha / \beta$ hydrolases, depolymerase-specific motifs can be derived. However, a data resource is still lacking which integrates sequence and structure information and provides tools for a systematic analysis of the sequence-structure-function relationship of PHA depolymerases. Therefore, the PHA Depolymerase Engineering Database (DED, http:// www.ded.uni-stuttgart.de) has been designed to assist a comprehensive analysis of sequences, the annotation of new sequences and the design of mutants. For the analysis of lipases and esterases, the Lipase Engineering Database (LED, http://www.led.uni-stuttgart.de) has previously been established and applied $[12,13]$. Comparison of the rules derived from the LED to the DED will help to understand differences of PHA depolymerases and other $\alpha / \beta$-hydrolases, and will relate experimentally observed properties of PHA depolymerases to their sequence.

\section{Construction and content}

To establish the PHA Depolymerase Engineering Database, the data warehouse system DWARF [14] has been applied. The DWARF system provides an automated retrieval tool to extract information on sequence, structure, or function from different source databases into a local data warehouse system. As a first step, 28 seed sequences of proteins with experimentally validated depolymerase activity (Table 1[15-33]) were stored in the database and annotated. These seed sequences were assigned to 6 previously described superfamilies based on their function [34]. Additionally the families of intracellular $\mathrm{nPHA}_{\mathrm{SCL}}$ depolymerases (lipase box), of which one family member has recently been described [35], and the family of periplasmatic PHA depolymerases including the PHA depolymerase from Rhodospirillum rubrum [7] were introduced. Thus, a total of 8 superfamilies were introduced:

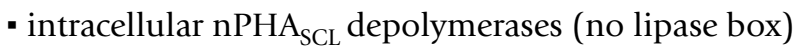

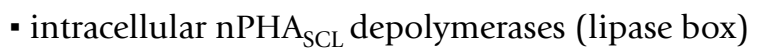

- intracellular $\mathrm{nPHA}_{\mathrm{MCL}}$ depolymerases
} 
Table I: Experimentally validated PHA depolymerases, which were used as seed sequences to set up the DED.

\begin{tabular}{|c|c|c|c|}
\hline Accession number (gi) & Organism & Family & Reference \\
\hline 3641686 & Ralstonia eutropha HI6 & Intracellular nPHA $\mathrm{SCL}_{\text {depolymerases (no lipase box) }}$ & {$[28]$} \\
\hline 75763431 & $\begin{array}{l}\text { Bacillus thuringiensis serovar israelensis ATCC } \\
35646\end{array}$ & Intracellular $\mathrm{nPHA}_{\mathrm{SCL}}$ depolymerases (lipase box) & {$[35]$} \\
\hline 22035160 & Rhodospirillum rubrum & Periplasmatic PHA depolymerases & {$[7]$} \\
\hline 130002 & Pseudomonas oleovorans & Intracellular nPHA $\mathrm{MCL}_{\text {depolymerases }}$ & {$[18]$} \\
\hline 21689574 & Pseudomonas putida & & {$[17]$} \\
\hline 130019 & Ralstonia pickettii & $\begin{array}{l}\text { Extracellular } \mathrm{dPHA}_{\mathrm{SCL}} \text { depolymerises } \\
\text { (catalytic domain type I) }\end{array}$ & [29] \\
\hline |77795 | & Alcaligenes faecalis & & [23] \\
\hline II 6744367 & Bacillus megaterium & & [48] \\
\hline 1730532 & Paucimonas lemoignei & & {$[20]$} \\
\hline 7385117 & Paucimonas lemoignei & & [31] \\
\hline 1657610 & Paucimonas lemoignei & & {$[15]$} \\
\hline 1621355 & Paucimonas lemoignei & & {$[15]$} \\
\hline 531464 & Paucimonas lemoignei & & {$[45]$} \\
\hline 531466 & Paucimonas lemoignei & & {$[45]$} \\
\hline 75538924 & Pseudomonas stutzeri & & [26] \\
\hline 5360565 & Ralstonia pickettii & & \\
\hline 1381030 & Ralstonia pickettii & & \\
\hline 4033618 & Acidovorax sp. TP4 & $\begin{array}{l}\text { Extracellular } \mathrm{dPHA}_{\mathrm{SCL}} \text { depolymerises } \\
\text { (catalytic domain type } 2 \text { ) }\end{array}$ & {$[25]$} \\
\hline 7209864 & Caldimonas manganoxidans & & [33] \\
\hline 565666 & Comamonas sp. & & {$[19]$} \\
\hline 75340123 & Delftia acidovorans & & {$[21]$} \\
\hline 47078657 & Schlegelella sp. KBIa & & {$[27]$} \\
\hline I 389770 & Streptomyces exfoliatus & & {$[24]$} \\
\hline 88192747 & Penicillium funiculosum & & {$[16]$} \\
\hline 15788987 & Paucimonas lemoignei & Extracellular $\mathrm{nPHA}_{\mathrm{SCL}}$ depolymerases & {$[6]$} \\
\hline 34452163 & Pseudomonas alcaligenes & Extracellular $\mathrm{dPHA}_{\mathrm{MCL}}$ depolymerases & {$[22]$} \\
\hline 29470160 & Pseudomonas alcaligenes & & [22] \\
\hline 21542177 & Pseudomonas fluorescens & & [30] \\
\hline
\end{tabular}

- periplasmatic PHA depolymerases

- extracellular $\mathrm{dPHA}_{\mathrm{SCL}}$ depolymerases (catalytic domain type 1)

- extracellular $\mathrm{dPHA}_{\mathrm{SCL}}$ depolymerases (catalytic domain type 2)

- extracellular nPHA $\mathrm{SCL}_{\mathrm{d}}$ depolymerases

- extracellular dPHA $\mathrm{MCL}_{\text {depolymerases }}$

The DWARF system was further applied to populate the database with sequences obtained from a pool of selected sequences, which have been annotated as "depolymerase" in the GenBank [36]. This was done by performing a BLAST search [37] of each seed sequence in the database against the selected sequence pool derived from the GenBank. As a final population step, BLAST searches against the non-redundant sequence database at NCBI http:// www.ncbi.nlm.nih.gov were performed for each sequence with an E-value cut-off of $\mathrm{E}=10^{-50}$ to populate the database with more sequences. Superfamilies were subdivided into homologous families, which were introduced based on sequence similarity and phylogenetic analysis (Fig. 1). New protein entries were assigned to homologous families and superfamilies by their sequence similarity.

Sequence entries with more than $98 \%$ sequence identity, which originate from the same source organism, were 
Homologous families of

intracellular $\mathrm{nPHAscl}$ depolymerases (no lipase box)

Homologous families of

extracellular dPHAscl depolymerases

(catalytic domain type 1)
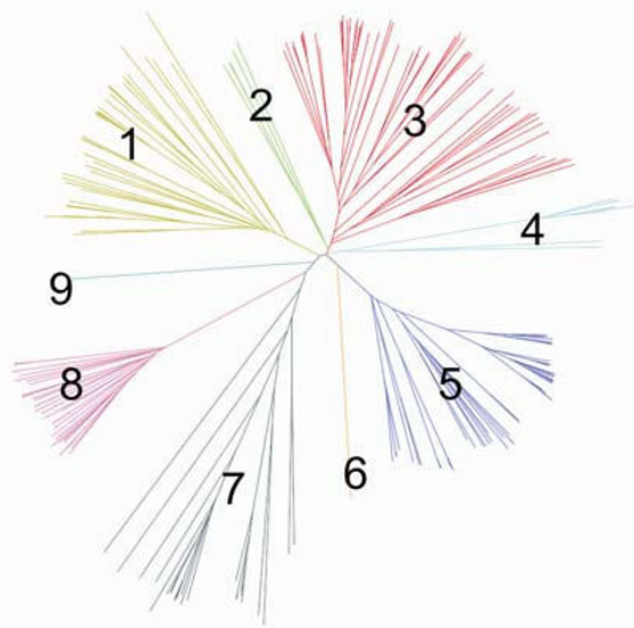

A

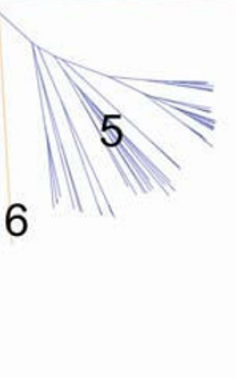

$14 \stackrel{15}{16}$

12
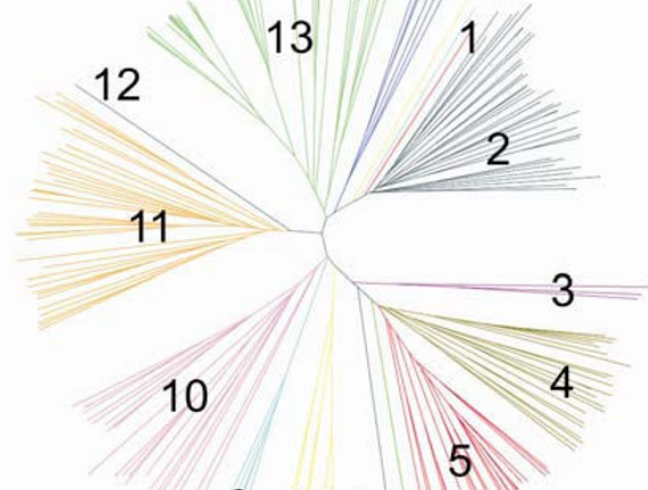

$\begin{array}{lll}9 & 8 & 7\end{array}$
B

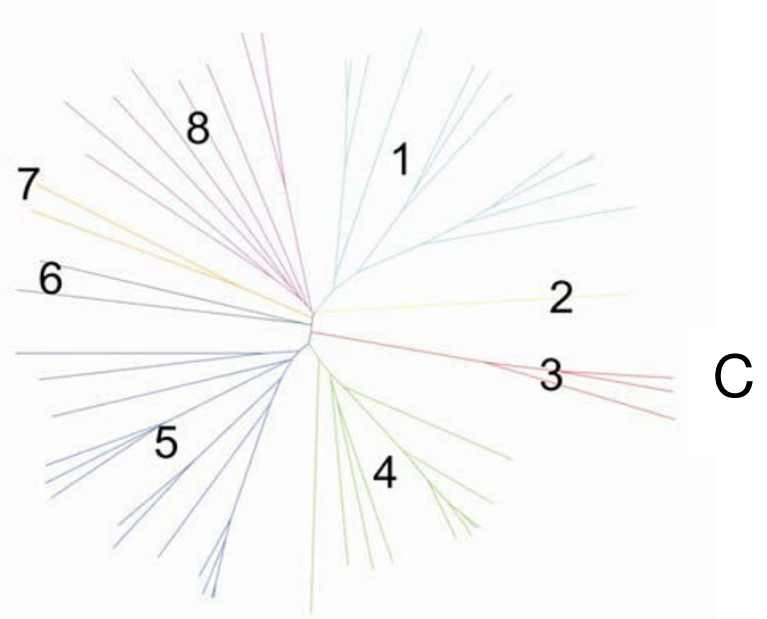

\section{Figure I}

Assignment of homologous families. Homologous families of intracellular $\mathrm{nPHA}_{\mathrm{SCL}}$ depolymerases (no lipase box) [A], extracellular $\mathrm{dPHA}_{\mathrm{SCL}}$ depolymerases (catalytic domain type I) [B], and extracellular $\mathrm{dPHA}_{\mathrm{SCL}}$ depolymerases (catalytic domain type 2) [C]. The homologous family number is indicated. 
assigned to a single protein entry. In case of multiple sequence entries for one protein, the longest sequence was set as reference sequence. For protein entries with available structure information, structural monomers were downloaded from the Protein Data Bank [38] and stored as structure entries. Secondary structure information was calculated applying the program DSSP [39] and displayed in the annotated multiple sequence alignments which are generated using ClustalW (v1.83) with default parameters [40]. Annotation information on structurally or functionally relevant residues (active site, disulfide bridges, signal peptide) was extracted from the NCBI entries and annotated in the DED. Information on experimentally validated depolymerases was manually added. Residues of the lipase box and the catalytic triad were manually annotated, which enables an easy identification of these residues for almost all PHA depolymerases based on multiple sequence alignments.

The PHA Depolymerase Engineering Database consists of 735 sequence entries which code for 587 different proteins. The proteins have been assigned to 8 superfamilies and 38 homologous families. The largest PHA depolymerase families are the intracellular $\mathrm{nPHA}_{\mathrm{SCL}}$ depolymerases (no lipase box) and the extracellular $\mathrm{dPHA}_{\mathrm{SCL}}$ depolymerases (catalytic domain type 1) with 224 and 234 protein entries, respectively, and account for $38 \%$ and $39 \%$ of all protein entries. Only one member of the family of periplasmatic PHA depolymerases was found, the PHA depolymerase of Rhodospirillum rubrum. For the families of extracellular $\mathrm{dPHA}_{\mathrm{SCL}}$ depolymerases (catalytic domain type 2) and the family of extracellular $\mathrm{nPHA}_{\mathrm{SCL}}$ depolymerases, structure information is available. Interestingly, two proteins from Cupriavidus taiwanensis and Ralstonia eutropha $\mathrm{H} 16$ which are annotated as "intracellular PHA depolymerase" in the GenBank were assigned to the family of extracellular $\mathrm{dPHA}_{\mathrm{SCL}}$ depolymerases (catalytic domain type 1) due to their sequence similarity (gi: 194292521, gi:74267419 [41]). The latter is reported to be highly active against artificial amorphous PHB granules, and is lacking a signal peptide, a linker domain, and a substrate binding domain. Another exception is the PHA depolymerase from Pseudomonas sp. which is annotated as "extracellular PHA depolymerase" in the GenBank but was assigned to the family of intracellular $\mathrm{nPHA}_{\mathrm{MCL}}$ depolymerases in the DED (gi:34452171).

\section{Utility and discussion}

The DWARF system is an integrative bioinformatics tool to build up protein family databases into a local data warehouse system. The DWARF system has previously been successfully applied to build up the Lipase Engineering Database $[12,13]$, the Cytochrome P450 Engineering Database http://www.cyped.uni-stuttgart.de[42], and the Medium-Chain Dehydrogenase/Reductase Engineering
Database http://www.mdred.uni-stuttgart.de[43]. A local data warehouse has the advantage of a common and consistent data structure which enables systematic analysis of complete protein families. The DED is the first data source that integrates information on sequence, structure, and function of PHA depolymerases in a systematic and consistent format.

\section{Web accessibility}

The database can be browsed on the level of sequence, structure, or organism. All protein entries are linked to the respective NCBI entries. Annotated multiple sequence alignments and phylogenetic trees that are visualized applying the program PHYLODENDRON http:// iubio.bio.indiana.edu/soft/molbio/java/apps are provided via the online accessible version of the DED at http:/ /www.ded.uni-stuttgart.de. For each family, information of amino acid conservation is given as calculated by PLOTCON [44]. For each homologous family and superfamily, family-specific profile hidden Markov models were calculated by the HMMER program http:// hmmer.janelia.org/to assist the classification of new PHA depolymerase sequences and the identification of new PHA depolymerase sequences from complete genomes in silico. A local BLAST interface is available to perform a BLAST search against the DED. A new dynamic user interface was developed which enables fast and easy integration of updated versions of the DED. The DED will be regularly updated by an automated script. For new sequence entries referring to a new structure in the Protein Data Bank (PDB), structure information is updated as well. New sequence and structure entries are classified into the homologous families and superfamilies based on their sequence identity.

\section{Analysis}

All PHA depolymerases in the DED possess a lipase box around the catalytic serine with a $\mathrm{Gx}_{1} \mathrm{Sx}_{2} \mathrm{G}$ sequence motif with the exception of the family of intracellular $\mathrm{nPHA}_{\mathrm{SCL}}$ depolymerases (no lipase box), which possess a catalytic cysteine instead of the lipase box. For particular PHA depolymerases it has been previously described that a hydrophobic residue is found at position $\mathrm{x}_{1}$ within the $\mathrm{Gx}_{1} \mathrm{Sx}_{2} \mathrm{G}$ motif $[4,9,45]$. This seems to be a common feature of almost all PHA depolymerases as seen from a systematic analysis of the DED family multiple sequence alignments. Thus, compared to other $\alpha / \beta$-hydrolases like lipases and esterases, where a polar residue is most frequently found at position $\mathrm{x}_{1}$, this conserved residue of the $\mathrm{Gx}_{1} \mathrm{Sx}_{2} \mathrm{G}$ motif might be relevant to differentiate between lipases or esterases and PHA depolymerases on sequence level. This hydrophobic residue is solvent exposed and located near the catalytic serine at the bottom of a deep cleft, as seen in the structure of the PHB depolymerase from Penicillium funiculosum (PDB entry 2D80) [46] (Fig. 
2 ). The hydrophobic residue at position $x_{1}$ is tryptophan and isoleucine for the families of intracellular $\mathrm{nPHA}_{\mathrm{SCL}}$ depolymerases (lipase box) and periplasmatic PHA depolymerases, respectively. For the family of intracellular $\mathrm{nPHA}_{\mathrm{MCL}}$ depolymerases, the residue at position $\mathrm{x}_{1}$ is valine for almost all proteins. Although not possessing a lipase box, but utilizing a catalytic cysteine, all family members of the family of intracellular $\mathrm{nPHA}_{\mathrm{SCL}}$ depolymerases (no lipase box) also have a hydrophobic residue (almost all valine) at position cysteine- 1 . While the hydrophobic residue at position $\mathrm{x}_{1}$ differs among the families of intracellular PHA depolymerases, leucine and isoleucine are the most frequent residues at this position for extracellular PHA depolymerases. While all proteins of the family of extracellular $\mathrm{dPHA}_{\mathrm{SCL}}$ depolymerases (catalytic domain type 2) possess a hydrophobic residue at position $\mathrm{x}_{1}$, only $81 \%$ of the proteins of the family of extracellular $\mathrm{dPHA}_{\mathrm{SCL}}$ depolymerases (catalytic domain type 1) have a hydrophobic residue at position $x_{1}$. All extracellular $\mathrm{DPHA}_{\mathrm{MCL}}$ depolymerases have an isoleucine at position $\mathrm{x}_{1}$. One exception is the family of extracellular $\mathrm{nPHA}_{\mathrm{SCL}}$ depolymerases, which neither possess a typical $\mathrm{Gx}_{1} \mathrm{Sx}_{2} \mathrm{G}$ motif nor has a hydrophobic residue a position $\mathrm{x}_{1}$. In this family, the $\mathrm{Gx}_{1} \mathrm{Sx}_{2} \mathrm{G}$ motif is altered to a AHSMG motif which can also be found in the family of Bacillus lipases (homologous family abH18.01 in the LED, http://www.led.uni-stuttgart.de). One family member of this special family is the PHB depolymerase from Paucimonas lemoignei, for which also structure information is available (PDB entry: 2VTV) [6,47]. This PHB

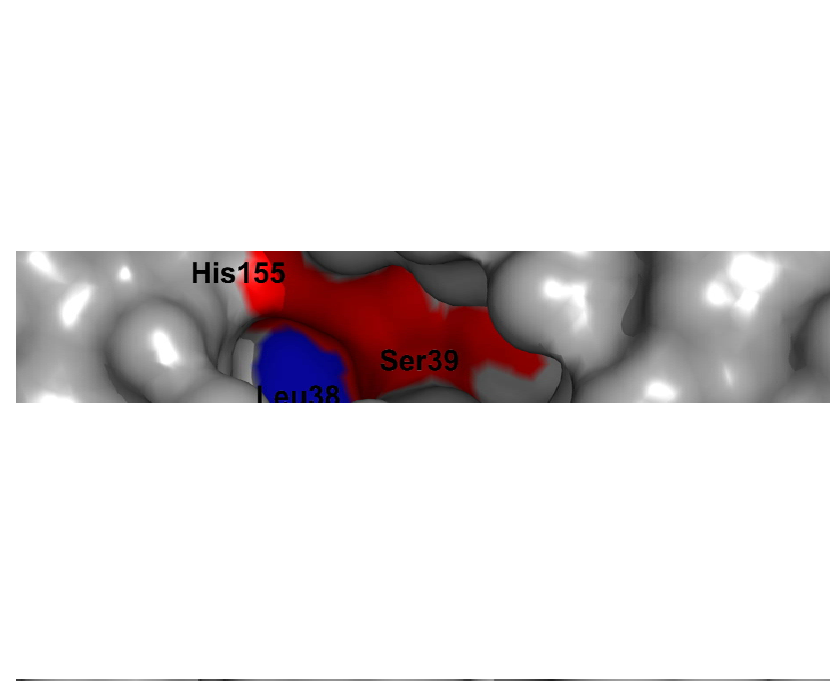

Figure 2

Top view of the binding site of the PHB Depolymerase from Penicillium funiculosum (PDB entry 2D80,

[46]). The catalytic residues are marked in red, the hydrophobic residue at position $x_{1}$ of the $G x_{1} S_{2} G$ motif is marked in blue. depolymerase has also special biochemical properties, as it is an extracellular $\mathrm{nPHA}_{\mathrm{SCL}}$ depolymerase degrading native granules, and is the only experimentally validated extracellular $\mathrm{PHA}_{\mathrm{SCL}}$ depolymerase not having a substrate binding domain. Within lipases and esterases, a polar residue is typically found at position $\mathrm{x}_{1}$. However, a few exception also exist among lipases and esterases, such as the of Candida antarctica lipase like family (homologous family abH37 in the LED) and the family of Bacillus carboxylesterases (abH11.1).

\section{Conclusion}

The PHA Depolymerase Engineering Database (DED) has been designed to serve as a navigation and analysis tool of PHA depolymerases. It serves as a platform to analyze sequence-structure-function relationships and to classify new sequences by providing multiple sequence alignments, phylogenetic trees, and family-specific profiles. The DED hence provides a valuable source of information to investigate the family of PHA depolymerases in a systematic way, to identify new proteins from genomes, and to distinguish between PHA depolymerases and lipases. Thus, it paves the way for a deeper understanding of biochemical properties of PHA depolymerases and to design PHA depolymerases with improved properties.

\section{Availability and requirements}

The PHA Depolymerase Engineering Database (DED) is online accessible at http://www.ded.uni-stuttgart.de. All information on families of sequence and structure data, as well as alignments, phylogenetic trees, and family-specific profiles can be accessed by manual download.

\section{Authors' contributions}

MK established and analyzed the database, and wrote the manuscript. TH carried out analysis and contributed to writing of the manuscript. FW programmed the dynamic user interface. VM contributed to establish the database. JP supervised the project and finalized the manuscript. All authors read and approved the final manuscript.

\section{Acknowledgements}

M.A. Prieto and D. Jendrossek are gratefully acknowledged for fruitful discussions. The work was carried out in the framework of the IP-project 'Sustainable Microbial and Biocatalytic Production of Advanced Functional Materials' (BIOPRODUCTION/NMP-2-CT-2007-0265I5) funded by the European Commission.

\section{References}

I. Anderson AJ, Dawes EA: Occurrence, metabolism, metabolic role, and industrial uses of bacterial polyhydroxyalkanoates. Microbiol Rev 1990, 54(4):450-472.

2. Prieto MA: From oil to bioplastics, a dream come true? Journal of Bacteriology 2007, I89(2):289-290.

3. Garcia B, Olivera ER, Minambres B, Fernandez-Valverde M, Canedo LM, Prieto MA, Garcia JL, Martinez M, Luengo JM: Novel biodegradable aromatic plastics from a bacterial source - Genetic and biochemical studies on a route of the phenylacetyl-CoA catabolon. Journal of Biological Chemistry 1999, 274(4I):29228-2924I. 
4. Tokiwa $Y$, Calabia BP: Degradation of microbial polyesters. Biotechnol Lett 2004, 26( I 5): I I8I-I I89.

5. Jendrossek D, Handrick R: Microbial degradation of polyhydroxyalkanoates. Annu Rev Microbiol 2002, 56:403-432.

6. Handrick R, Reinhardt S, Focarete ML, Scandola M, Adamus G, Kowalczuk $M$, Jendrossek $D$ : A new type of thermoalkalophilic hydrolase of Paucimonas lemoignei with high specificity for amorphous polyesters of short chain-length hydroxyalkanoic acids. J Biol Chem 200I, 276(39):362I 5-36224.

7. Handrick R, Reinhardt S, Kimmig P, Jendrossek D: The "intracellular" poly(3-hydroxybutyrate) (PHB) depolymerase of Rhodospirillum rubrum is a periplasm-located protein with specificity for native PHB and with structural similarity to extracellular PHB depolymerases. I Bacteriol 2004, I 86(2I):7243-7253.

8. Finn RD, Tate J, Mistry J, Coggill PC, Sammut SJ, Hotz HR, Ceric G, Forslund K, Eddy SR, Sonnhammer EL, et al:: The Pfam protein families database. Nucleic Acids Res 2008:D28I-288.

9. Jaeger KE, Steinbüchel A, Jendrossek D: Substrate specificities of bacterial polyhydroxyalkanoate depolymerases and lipases: bacterial lipases hydrolyze poly(omega-hydroxyalkanoates). Appl Environ Microbiol 1995, 6 I (8):3। I 3-3। I8.

10. Behrends A, Klingbeil B, Jendrossek D: Poly(3-hydroxybutyrate) depolymerases bind to their substrate by a C-terminal located substrate binding site. Fems Microbiol Lett 1996, I43(23): $191-194$.

II. Handrick R, Reinhardt S, Jendrossek D: Mobilization of poly(3hydroxybutyrate) in Ralstonia eutropha. J Bacteriol 2000, I 82(20):5916-59|8.

12. Pleiss J, Fischer M, Peiker M, Thiele C, Schmid RD: Lipase engineering database - Understanding and exploiting sequencestructure-function relationships. J Mol Catal B-Enzym 2000, I0(5):49|-508.

13. Fischer M, Pleiss J: The Lipase Engineering Database: a navigation and analysis tool for protein families. Nucleic Acids Research 2003, 3 I(I):3I9-32I.

14. Fischer M, Thai QK, Grieb M, Pleiss J: DWARF - a data warehouse system for analyzing protein families. BMC Bioinformatics 2006, 7:495.

15. Briese BH, Schmidt B, Jendrossek D: Pseudomonas lemoignei has five poly(hydroxyalkanoic acid) (PHA) depolymerase genes: a comparative study of bacterial and eucaryotic PHA depolymerases. J Environ Polym Degrad 1994, 2:75-87.

16. Brucato CL, Wong SS: Extracellular poly(3-hydroxybutyrate) depolymerase from Penicillium funiculosum: general characteristics and active site studies. Arch Biochem Biophys 1991, 290(2):497-502.

17. de Eugenio LI, Garcia P, Luengo JM, Sanz JM, Roman JS, Garcia JL, Prieto MA: Biochemical evidence that phaZ gene encodes a specific intracellular medium chain length polyhydroxyalkanoate depolymerase in Pseudomonas putida KT2442: characterization of a paradigmatic enzyme. J Biol Chem 2007, 282(7):495I-4962.

18. Huisman GW, Wonink E, Meima R, Kazemier B, Terpstra P, Witholt B: Metabolism of poly(3-hydroxyalkanoates) (PHAs) by Pseudomonas oleovorans. Identification and sequences of genes and function of the encoded proteins in the synthesis and degradation of PHA. J Biol Chem | 99|, 266(4):219|-2198.

19. Jendrossek D, Backhaus M. Andermann M: Characterization of the Extracellular Poly(3-Hydroxybutyrate) Depolymerase of Comamonas Sp and of Its Structural Gene. Can J Microbiol 1995, 41:160-169.

20. Jendrossek D, Muller B, Schlegel HG: Cloning and characterization of the poly(hydroxyalkanoic acid)-depolymerase gene locus, phaZI, of Pseudomonas lemoignei and its gene product. Eur J Biochem 1993, 218(2):701-710.

21. Kasuya KI, Inoue Y, Tanaka T, Akehata T, Iwata T, Fukui T, Doi Y: Biochemical and molecular characterization of the polyhydroxybutyrate depolymerase of Comamonas acidovorans YM isolated from freshwater. Appl Environ Microb I609, 63( I 2):4844-4852.

22. Kim DY, Kim HC, Kim SY, Rhee YH: Molecular characterization of extracellular medium-chain-length poly(3-hydroxyalkanoate) depolymerase genes from Pseudomonas alcaligenes strains. J Microbiol 2005, 43(3):285-294.
23. Kita K, Mashiba S, Nagita M, Ishimaru K, Okamoto K, Yanase H, Kato $\mathrm{N}$ : Cloning of poly(3-hydroxybutyrate) depolymerase from a marine bacterium, Alcaligenes faecalis AEI22, and characterization of its gene product. Biochim Biophys Acta 1997, I352(1): I | 3-122

24. Klingbeil B, Kroppenstedt RM, Jendrossek D: Taxonomic identification of Streptomyces exfoliatus KIO and characterization of its poly(3-hydroxybutyrate) depolymerase gene. Fems Microbiol Lett 1996, 142(2-3):215-22I.

25. Kobayashi T, Sugiyama A, Kawase Y, Saito T, Mergaert J, Swings J: Biochemical and genetic characterization of an extracellular poly(3-hydroxybutyrate) depolymerase from Acidovorax sp strain TP4. J Environ Polym Degr 1999, 7(1):9-18.

26. Ohura $\mathrm{T}$, Kasuya $\mathrm{KI}$, Doi $\mathrm{Y}$ : Cloning and characterization of the polyhydroxybutyrate depolymerase gene of Pseudomonas stutzeri and analysis of the function of substrate-binding domains. Appl Environ Microbiol 1999, 65(1):189-197.

27. Romen F, Reinhardt S, Jendrossek D: Thermotolerant poly(3hydroxybutyrate)-degrading bacteria from hot compost and characterization of the PHB depolymerase of Schlegelella sp KB I a. Arch Microbiol 2004, I 82(2-3): 157-164.

28. Saegusa $H$, Shiraki $M$, Kanai $C$, Saito $T$ : Cloning of an intracellular Poly[D(-)-3-Hydroxybutyrate] depolymerase gene from Ralstonia eutropha $\mathrm{HI} 6$ and characterization of the gene product. J Bacteriol 200I, I 83(I):94-100.

29. Saito T, Suzuki K, Yamamoto J, Fukui T, Miwa K, Tomita K, Nakanishi S, Odani S, Suzuki J, Ishikawa K: Cloning, nucleotide sequence, and expression in Escherichia coli of the gene for poly(3hydroxybutyrate) depolymerase from Alcaligenes faecalis. J Bacteriol 1989, I7I(1):184-189.

30. Schirmer A, Jendrossek D: Molecular characterization of the extracellular poly(3-hydroxyoctanoic acid) [P(3HO)] depolymerase gene of Pseudomonas fluorescens GK 13 and of its gene product. J Bacteriol 1994, I76(22):7065-7073.

3I. Schober U, Thiel C, Jendrossek D: Poly(3-hydroxyvalerate) depolymerase of Pseudomonas lemoignei. Appl Environ Microbiol 2000, 66(4): I385-1392.

32. Takaku H, Kimoto A, Kodaira S, Nashimoto M, Takagi M: Isolation of a Gram-positive poly(3-hydroxybutyrate) (PHB)-degrading bacterium from compost, and cloning and characterization of a gene encoding PHB depolymerase of Bacillus megaterium N-18-25-9. Fems Microbiology Letters 2006, 264(2): $152-159$.

33. Takeda M, Kitashima K, Adachi K, Hanaoka Y, Suzuki I, Koizumi Jl: Cloning and expression of the gene encoding thermostable poly(3-hydroxybutyrate) depolymerase. J Biosci Bioeng 2000, 90(4):4|6-42I.

34. Jendrossek D, Handrick R: Diversität bakterieller PHBDepolymerasen am Beispiel von Paucimonas gen. nov. lemoignei comb. nov. BIOspektrum 200I, 7:.

35. Tseng CL, Chen HJ, Shaw GC: Identification and characterization of the Bacillus thuringiensis phaZ gene, encoding new intracellular poly-3-hydroxybutyrate depolymerase. J Bacteriol 2006, I 88(2 I):7592-7599.

36. Benson DA, Karsch-Mizrachi I, Lipman DJ, Ostell J, Wheeler DL: GenBank. Nucleic Acids Res 2007:D2 I-25.

37. Altschul SF, Madden TL, Schaffer AA, Zhang J, Zhang Z, Miller W, Lipman DJ: Gapped BLAST and PSI-BLAST: a new generation of protein database search programs. Nucleic Acids Res 1997, 25(17):3389-3402.

38. Berman HM, Westbrook J, Feng Z, Gilliland G, Bhat TN, Weissig H, Shindyalov IN, Bourne PE: The Protein Data Bank. Nucleic Acids Res 2000, 28(I):235-242.

39. Kabsch W, Sander C: Dictionary of protein secondary structure: pattern recognition of hydrogen-bonded and geometrical features. Biopolymers 1983, 22(I 2):2577-2637.

40. Thompson JD, Higgins DG, Gibson T): CLUSTAL W: improving the sensitivity of progressive multiple sequence alignment through sequence weighting, position-specific gap penalties and weight matrix choice. Nucleic Acids Res 1994 22(22):4673-4680.

4I. Abe T, Kobayashi T, Saito T: Properties of a novel intracellular poly(3-hydroxybutyrate) depolymerase with high specific activity (PhaZd) in Wautersia eutropha H 16. Journal of Bacteriology 2005, I87(20):6982-6990. 
42. Fischer M, Knoll M, Sirim D, Wagner F, Funke S, Pleiss J: The Cytochrome P450 Engineering Database: a navigation and prediction tool for the cytochrome $\mathbf{P 4 5 0}$ protein family. Bioinformatics 2007, 23(I5):2015-2017.

43. Knoll M, Pleiss J: The Medium-Chain Dehydrogenase/Reductase Engineering Database: A systematic analysis of a diverse protein family to understand sequence-structure-function relationship. Protein Sci 2008, 17:1689-1697.

44. Rice P, Longden I, Bleasby A: EMBOSS: the European Molecular Biology Open Software Suite. Trends Genet 2000, 1 6(6):276-277.

45. Jendrossek D, Frisse A, Behrends A, Andermann M, Kratzin HD, Stanislawski T, Schlegel HG: Biochemical and molecular characterization of the Pseudomonas lemoignei polyhydroxyalkanoate depolymerase system. J Bacteriol 1995, 177(3):596-607.

46. Hisano T, Kasuya K, Tezuka Y, Ishii N, Kobayashi T, Shiraki M, Oroudjev $E$, Hansma H, Iwata T, Doi $Y$, et al.: The crystal structure of polyhydroxybutyrate depolymerase from Penicillium funiculosum provides insights into the recognition and degradation of biopolyesters. J Mol Biol 2006, 356(4):993-1004.

47. Papageorgiou AC, Hermawan S, Singh CB, Jendrossek D: Structural basis of poly(3-hydroxybutyrate) hydrolysis by PhaZ7 depolymerase from Paucimonas lemoignei. J Mol Biol 2008, 382(5): I I84- II 194.

48. Takaku $H$, Kimoto $A$, Kodaira $S$, Nashimoto $M$, Takagi M: Isolation of a Gram-positive poly(3-hydroxybutyrate) (PHB)-degrading bacterium from compost, and cloning and characterization of a gene encoding PHB depolymerase of Bacillus megaterium N-18-25-9. Fems Microbiol Lett 2006, 264(2): $152-159$

Publish with Bio Med Central and every scientist can read your work free of charge

"BioMed Central will be the most significant development for disseminating the results of biomedical research in our lifetime. "

Sir Paul Nurse, Cancer Research UK

Your research papers will be:

- available free of charge to the entire biomedical community

- peer reviewed and published immediately upon acceptance

- cited in PubMed and archived on PubMed Central

- yours - you keep the copyright
BioMedcentral 